\title{
Continuing Education On Qualitative Risk Assessment: Improving The Understanding Of Risk
}

\author{
Marcela G. Ribeiro, PhD \\ Marco A. Bussacos \\ Walter dos R. Pedreira Filho, PhD \\ Fundação Jorge Duprat Figueiredo de Segurança \\ e Medicina do Trabalho, São Paulo, SP, Brazil
}

doi: 10.19044/esj.2016.v12n12p11 URL:http://dx.doi.org/10.19044/esj.2016.v12n12p11

\begin{abstract}
Despite a common agreement that environmental and occupational health \& safety professionals must learn about risk early in formal education, such matters still remain underrepresented in most education programs. This paper describes the development and use of an instructional material aimed at exploring and improving health \& safety professionals' understanding on what risk really means, and on what is needed to its technical assessment. After reading a text depicting the technical and contextual aspects of unintended technological accidents, participants were asked to rank such events regarding its risk. Next, they had to explain what criteria they adopted, and also to compare their results with reference values, discussing the differences. Participants' statements were collected and compiled. The ensuing discussion involved the resignification of the ideas raised by them, introducing the scientific meaning into a technical context. The proposed practice presented consistent results becoming an alternative resource to teach risk in a way participants share opinions based on their previous knowledge and begin to deal with the idea of evaluating risks in a scientifically reasoned basis.
\end{abstract}

Keywords: Continuing education; risk; risk assessment; occupational health \& safety

\section{Introduction}

Risk is inherent to everyday life. In its simplest meaning, it can be seen as a concept created by humans to give meaning and to cope with dangerous situations and with uncertainties of ordinary life (Slovic \& Weber, 2002). In spite of that, meanings of risk concepts have changed and evolved over time (Aven, 2012; Jackson, Allum, \& Gaskell, 2006). Among different 
connotations regarding the use of the word 'risk', its association with anything that could cause harm; its use to express the assessment of probability and extent of adverse outcomes; and the weighing of gain and losses, e.g. cost/benefit analysis, are more often found (Aven, 2010; Zinn, 2008).

In literature, several definitions can be found for the concept of risk. Many authors exhaustively wrote about and discussed such concepts, its rationales, strengths and weaknesses (Aven, 2012; Aven, Renn, \& Rosa, 2011; Zinn, 2008; Boholm, 2012). Despite the lack of a commonly accepted definition, the distinction of reality and possibility is a shared element in all risk concepts, either in science or in public understanding (Aven \& Kristensen, 2005; Renn, 1998b; ISO, 2009a, 2009b, 2009c). According to Althaus (Althaus, 2005), "the conceptual understanding of risk conveys risk to be something that is open to a multitude of converse possibilities and interpretations” (p. 570). Such possibilities and interpretations were developed and used according to the needs of specific disciplines and areas.

Along with semantic and ontological discussions, man-made risks are increasingly becoming part of human environment and must be recognized and understood to be properly managed (International Risk Governance Council [IRGC] , 2005; 2010; European Agency for Safety and Health at Work, 2013; Cleeland, 2011; Takala \& Hamalainen, 2009; Koukoulaki, 2010). During the past 40 years, the field of risk analysis has grown rapidly, focusing on issues such as identification, quantification, and characterization of threats to human health and to the environment, as well as its respective communication, mitigation, and decision making process (Slovic \& Weber, 2002; Hovden, Albrechtsen, \& Herrera, 2010; Badri, Gbodossou, \& Nadeau, 2012).

From the technical-scientific point of view, risk can be considered an objectively measurable or observable event or danger (Aven, 2011; Aven, 2012a; ISO, 2009a; ISO, 2009b; ISO, 2009c). Risk assessment, in its turn, comprises the scientific process of defining the components of risk quantitatively, semi-quantitatively, or qualitatively (Zalk \& Nelson, 2008). It is based on experts' empirical calculation of the probability of event occurrence and the amount or extent of damage, excluding societal and subjective factors of such calculations, as much as possible (Singley, 2004).

According to the US Environmental Protection Agency, "risk is the chance of harmful effects to human health or to ecological systems, resulting from exposure to an environmental stressor" (Environmental Protection Agency, 2012). The Canadian Centre for Occupational Health and Safety defines risk as "the likelihood or probability that a person will be harmed or experience an adverse health effect if exposed, under a given condition, to a hazard, which in turn comprises a wide range of sources, such 
as substances; situations; processes or practices" (Canadian Centre for Occupational Health and Safety, 2006; 2009).

In addition, risk assessment can be defined as a comprehensive process carried out to estimate the probability of adverse effects on human health and environment, as a consequence of exposure to a specific hazard or to an environmental stressor. It aims at ensuring that living beings, as well as the environment, will not be negatively impacted or impaired. It involves: (i) hazard identification; (ii) exposure evaluation, taking into account both the severity and the likelihood of an injury or illness occur; and (iii) evaluation of the risk associated with each hazard. Risk assessment also allows the identification of actions that, once put in place, effectively eliminate or control the risk (Alli, 2008; Pickering \& Cowley, 2010).

To this end, if either the risk is not recognized, or the meaning of risk is not clearly defined, risk assessment will certainly fail (Caponecchia, 2010). To avoid failures during the process, professionals must be prepared to recognize multiple and context-dependent conceptions of risk, and make the assessment following rational scientific procedures, disregarding personal beliefs, emotions and values.

Education on environmental and occupational health \& safety issues comprises, among others, learning about risk and its assessment tools (Covvit, Harris, \& Anderson, 2013; Jonckheer \& De Brouwer, 2009). However, tailoring up a proactive professional, conscious of what is at stake, and thus, able to avoid risk misjudgment, requires more than merely training programs on the use of such tools. Professionals must be prepared to think critically about risk, its different rationales and approaches, as well as be aware of both perceptual filters and contextual factors influencing risk assessment and management (Brosseau \& Fredrickson, 2009; Borys, n.d.).

Despite a common agreement that risk must be taught early in formal education, such matter still remains underrepresented in most education programs (Gardner, Jones, Taylor, Forrester \& Robertson, 2010; Zint, 2001; Covitt, Gomez-Schmidt, \& Zint, 2005; Jonckheer \& De Brouwer, 2009; Pisaniello et al., 2013; Rosen, Caravanos, Milek \& Udasin, 2011). Many obstacles have already been identified to embed education on risk into curricula. Among them are: the lack of suitable instructional material for different educational levels; the fact that risk itself and its related matters are not seen as an academic content; and a lack of competence to approach the subject (European Agency for Safety and Health at Work, 2010; National Research Council, 2000).

This paper describes the development and use of an instructional material aimed at fostering a discussion, exploring and enhancing health and safety professionals' ideas and arguments on what risk really means, and on what is needed to its recognition and technical assessment. 


\section{Materials and methods Participants}

The sample was composed of 142 participants divided into five independent groups. The participants were enrolled in short-duration training course (45 hours) on qualitative risk assessment of chemicals. This course was yearly offered from 2007 to 2011, in an institute focused on conducting research, training, and education in occupational safety \& health issues. The groups were randomly constituted regarding gender, educational level and profession. Nevertheless, all participants worked at environmental or occupational related areas. Groups’ characteristics are shown in Table 1.

Table 1 Groups' characteristics.

\begin{tabular}{cccccc} 
Group & $\mathbf{G}_{\mathbf{1}}$ & $\mathbf{G}_{\mathbf{2}}$ & $\mathbf{G}_{\mathbf{3}}$ & $\mathbf{G}_{\mathbf{4}}$ & $\mathbf{G}_{\mathbf{5}}$ \\
\hline Participants & & & & & \\
n per group & 19 & 38 & 21 & 40 & 24 \\
Female & 10 & 13 & 14 & 20 & 10 \\
Male & 9 & 25 & 7 & 20 & 14 \\
\hline Educational Level & & & & & \\
$\quad$ Major degree & 12 & 34 & 17 & 37 & 13 \\
High school or Technician certificate & 7 & 4 & 4 & 3 & 11 \\
\hline Area of expertise & & & & & \\
*Occupational Safety or Environmental & 18 & 27 & 9 & 10 & 17 \\
$* *$ Occupational Health & 1 & 11 & 12 & 27 & - \\
\hline
\end{tabular}

*Engineer; architect; chemist; pharmacist; occupational safety technician; chemist technician; economist; human resource professional. **Including surveillance: physician; nurse; biologist; physical therapist; veterinarian; dentist; audiologist; social and human service assistant; political scientist.

\section{Instrument}

The instrument comprises a reading material and a handout containing a single question and a table. The reading material was drawn up seeking to depict just the technical and contextual aspects of 14 unintended technological accidents and their outcomes for both science and society. It covered a comprehensive set of hazardous activities, including: 4 hazards associated with nuclear technology (Chernobyl, Chelyabisnk, Three Mile Island and Tokaimura); 4 hazards associated with chemical industry (Bhopal, Minamata, Seveso and Texas City); 3 hazards associated with medical and pharmaceutical industry (L-tryptophane, thalidomide and silicone implants); 2 hazards associated to oil tankers (Exxon-Valdez and Prestige); and 1 hazard associated to large constructions (Malpasset dam). The events were displayed alphabetically in the reading material and in the handout.

The description of the accidents was downloaded from data available at the Hazardcards Website (Learning Lab, 2005a). Hazardcards is a science communication educational resource aimed at fostering the debate about technological hazards (Learning Lab, 2005b; Nielsen, 2005). It is a card 
game to be played like Top Trumps. In addition to a brief description of the accident, each card is broken down into the following categories: hazard, casualties, range, fear factor and media effect. Each category has a score value. In this work, besides the technical aspects and contextual consequences of the accidents, the Hazard score associated with such events was used. Such value was based on an expert assessment of the potential dangers of the technologies. Despite named as 'hazard', it is a risk assessment carried out using a variant of decision analysis and the normal accident theory (Learning Lab, 2005c). It is an expert evaluation that excludes factors such as cultural values, ethical principles, and democratic dialogue. It was named as expert reference value, used for comparison purposes only.

\section{Data collection and in-class discussion}

The activity was administered to participants at the beginning of the training course. Firstly, they were asked to read the text described above. After that, participants were asked to rank such events at the handout, attributing score 1 to the highest risk and 14 to the lowest risk, ranking all the other events accordingly. Each participant completed the rank individually. There was no time for any specific preparation or discussion with other classmates.

Data was collected, analyzed and the findings were then orally discussed within groups. Discussions focused on why they scored the events in that way, what factors drew their attention, and what criteria were adopted for ranking. Respondents were not directly asked to judge the risk from a specific point of view, such as societal benefits, number of deaths, or complexity of the technology.

Next, participants compared their results with the expert reference values, and the differences formed the basis for further discussions regarding meanings of risk, risk perception and risk assessment. How and when these meanings intersected, confounded, and distinguished from each other was also discussed.

\section{Data analysis}

Data was analyzed using SAS 9.2 for Windows. All statistical tests were performed adopting the significance level $(\alpha) 5 \%(p<0.05)$.-For each group, the 'rank' variable was obtained applying the Wilcoxon Scores test for the 14 events, according to the risk score attributed by the groups. Kruskal-Wallis test was used for 'rank' variable inter-groups comparison within each event. It tested the null hypothesis $\left(\mathrm{H}_{0}\right)$ that all groups ranked the events in a similar way. The null hypothesis can be rejected when the significance of ChiSq $\left(\chi^{2}\right)$ is less than $\alpha$ (computed $p$-value $<0.05$ ). On the 
other hand, if the statistic is not significant ( $p$-value $>0.05$ ) then no differences exist between the samples.

Pearson correlation coefficients $(\rho)$ were calculated to verify whether there was a linear relationship inter-groups as well as the strength of the linear relationship. The larger the $\rho$ value, the stronger the linear relationship (Cohen, 1988). The hypothesis about the linear relationship inter-groups was verified testing the level of statistical significance ( $p$-value) of the correlation coefficient. The smaller the $p$ value, the higher the relationship significance. Pearson correlation coefficients $(\rho)$ were also calculated to verify the strength of the linear relationship between expert reference values and groups’ rank values.

Cronbach's alpha was used as a measure of the internal consistency regarding rank ordering concordance inter-groups. It is an index of reliability associated with the variation accounted for by the true score of the variable that is being measured. Alpha coefficient ranges in value from 0 to 1 and the higher the score, the more reliable the generated rank is.

In addition, a so-called variable'dif was obtained for each event within each group. It corresponds to the difference between the expert reference value and the groups' rank value. The larger the 'dif' value, the larger the discrepancy between expert and groups' opinion. Kruskal-Wallis test was used to check the null hypothesis $\left(\mathrm{H}_{0}\right)$ that all groups framed and categorized events according to the hazards nature in a similar way.

\section{Results and Discussion Statistical analysis}

Table 2 presents how the groups ranked the 14 events, regarding their risk. The low significance level of Kruskal-Wallis test $(p>0.05)$ indicates that the five groups interpreted most of the 14 events in a similar way. Exceptions were found to Exxon-Valdez ( $p$-value 0.004), L-Tryptophane ( $p$ value 0.028), Prestige ( $p$-value 0.04) and Thalidomide ( $p$-value 0.027). Despite such minor differences, the standardized Cronbach's alpha obtained value of 0.9547 suggests a strong internal consistency, thus reinforcing that the five different groups ranked the events in a very similar way.

Table 2 Events ranking and statistical significance of inter-groups similarity.

\begin{tabular}{cccccccccc} 
& \multicolumn{1}{c}{} & \multicolumn{3}{c}{${ }^{\mathbf{a}}$ Rank } & & \multicolumn{3}{c}{$\begin{array}{c}{ }^{\mathbf{b}} \text { Kruskal-Wallis } \\
\text { test }\end{array}$} \\
\cline { 2 - 10 } & $\begin{array}{c}{ }^{\mathbf{c}} \text { Ref. } \\
\text { value }\end{array}$ & $\mathbf{G}_{\mathbf{1}}$ & $\mathbf{G}_{\mathbf{2}}$ & $\mathbf{G}_{\mathbf{3}}$ & $\mathbf{G}_{\mathbf{4}}$ & $\mathbf{G}_{\mathbf{5}}$ & $\mathbf{C h i S q}$ & $\mathbf{p}$ \\
\hline Bhopal & $\mathbf{5}$ & 1 & 2 & 2 & 2 & 1 & 4.284 & 0.3689 \\
Chelyabinsk & $\mathbf{1}$ & 3 & 3 & 3 & 3 & 3 & 5.303 & 0.2575 \\
Chernobyl & $\mathbf{2}$ & 2 & 1 & 1 & 1 & 2 & 9.274 & 0.0546 \\
Exxon-Valdez & $\mathbf{1 2}$ & 8 & 11 & 7 & 9 & 13 & 15.309 & $* 0.0041$ \\
L-Tryptophane & $\mathbf{7}$ & 13 & 13 & 13 & 13 & 10 & 10.856 & $* 0.0282$
\end{tabular}




\begin{tabular}{ccccccccc} 
Malpasset & $\mathbf{1 0}$ & 12 & 10 & 12 & 11 & 11 & 1.9849 & 0.7385 \\
Minamata & $\mathbf{8}$ & 4 & 4 & 5 & 4 & 5 & 4.4433 & 0.3493 \\
Prestige & $\mathbf{1 4}$ & 9 & 14 & 11 & 12 & 14 & 15.4307 & $* 0.0039$ \\
Seveso & $\mathbf{9}$ & 5 & 5 & 4 & 5 & 6 & 7.4235 & 0.1151 \\
Silicone & $\mathbf{1 1}$ & 14 & 12 & 14 & 14 & 12 & 7.5412 & 0.1099 \\
Implants & & & & & & & & \\
Texas City & $\mathbf{1 3}$ & 6 & 8 & 6 & 6 & 8 & 5.0832 & 0.2789 \\
Thalidomide & $\mathbf{6}$ & 11 & 7 & 10 & 8 & 4 & 10.9835 & $* 0.0268$ \\
Three Mile & $\mathbf{3}$ & 10 & 9 & 9 & 10 & 9 & 1.4734 & 0.8313 \\
Island & & & & & & & & \\
Tokaimura & $\mathbf{4}$ & 7 & 6 & 8 & 7 & 7 & 4.5916 & 0.3318 \\
\hline
\end{tabular}

${ }^{a}$ Wilcoxon Scores treatment $(p<0.0001) ;{ }^{b}$ inter-groups events similarity $(p<0.05) ;{ }^{c}$ expert estimate (hazard value).

Pearson correlation coefficients are presented in Table 3. The $\rho$ values higher than 0.7 , coupled with computed $p$-values lower than 0.05 , suggest a high significance level of a strong linear relationship inter-groups $\left(G_{1}-G_{5}\right)$, also indicating that events were ranked similarly by the groups. The obtained $\rho$ values between 0.3 and 0.5 indicate a small to medium correlation of a linear relationship. Additionally, computed $p$-values near to, or higher than 0.05 , indicate a lower significance level of the statistical test. Once coupled, such results indicate differences between expert analysis and groups' analysis $\left(G_{1}, G_{3}, G_{4}\right)$. The obtained $\rho$ values higher than 0.6 (medium to strong correlation of a linear relationship), coupled with computed $p$-values lower than 0.05, suggest similarities between expert analysis and $\mathrm{G}_{2}$ and $\mathrm{G}_{5}$ groups' analysis. Nevertheless, inter-groups analysis presents even higher $\rho$ values and lower $p$-values.

Table 3 Pearson correlation coefficients.

\begin{tabular}{c|ccccc}
\multicolumn{1}{c}{ Group 1 } & Group 2 & Group 3 & Group 4 & Group 5 \\
\hline Group 1 & 1 & & & \\
& & & & \\
\hline Group 2 & 0.85495 & 1 & & \\
& $p<0.0001$ & & & & \\
\hline Group 3 & 0.97363 & 0.88571 & 1 & \\
& $p<0.0001$ & $p<0.0001$ & & & \\
\hline Group 4 & 0.95165 & 0.95604 & 0.96923 & 1 & \\
& $p<0.0001$ & $p<0.0001$ & $p<0.0001$ & & \\
\hline Group 5 & 0.73626 & 0.93846 & 0.76703 & 0.87253 & \\
& $p<0.0027$ & $p<0.0001$ & 0.0014 & $p<0.0001$ & 0.72747 \\
\hline Ref. value & 0.39780 & 0.67033 & 0.45495 & 0.52527 & \\
& $p=0.1590$ & $p=0.0087$ & $p=0.1022$ & $p=0.0537$ & $p=0.0032$ \\
\hline
\end{tabular}

The 14 events, grouped according to hazard category, are presented in Table 4. The variable 'dif' corresponds to the difference between the expert reference value and groups' rank value (Table 2). The larger the 'dif' value, the larger the discrepancy between expert and groups' analysis. Additionally, 
positive 'dif' values indicate that the risk within such event was overestimated by the groups and negative 'dif' values indicate risk underestimation by the groups. The high significance level of Kruskal-Wallis test indicates that the five groups framed the events according to its hazards categories.

Table 4 Events displayed into hazard categories.

\begin{tabular}{|c|c|c|c|c|c|}
\hline $\begin{array}{c}\text { Hazard category } \\
\text { Event }\end{array}$ & $\operatorname{dif}_{\mathrm{G} 1}$ & $\operatorname{dif}_{\mathrm{G} 2}$ & $\operatorname{dif}_{\mathrm{G} 3}$ & $\operatorname{dif}_{\mathrm{G} 4}$ & $\operatorname{dif}_{\mathrm{G} 5}$ \\
\hline \multicolumn{6}{|l|}{ Chemicals } \\
\hline Bhopal & 4 & 3 & 3 & 3 & 4 \\
\hline Minamata & 4 & 4 & 3 & 4 & 3 \\
\hline Seveso & 4 & 4 & 5 & 4 & 3 \\
\hline Texas City & 7 & 5 & 7 & 7 & 5 \\
\hline \multicolumn{6}{|l|}{ Nuclear } \\
\hline Chelyabinsk & -2 & -2 & -2 & -2 & -2 \\
\hline Chernobyl & 0 & 1 & 1 & 1 & 0 \\
\hline Three Mile Island & -7 & -6 & -6 & -7 & -6 \\
\hline Tokaimura & -3 & -2 & -4 & -3 & -3 \\
\hline \multicolumn{6}{|l|}{ Environment (oil) } \\
\hline Exxon-Valdez & 4 & 1 & 5 & 3 & -1 \\
\hline Prestige & 5 & 0 & 3 & 2 & 0 \\
\hline \multicolumn{6}{|l|}{ Medical } \\
\hline L-Tryptophane & -6 & -6 & -6 & -6 & -3 \\
\hline Silicone Implants & -3 & -1 & -3 & -3 & -1 \\
\hline Thalidomide & -5 & -1 & -4 & -2 & 2 \\
\hline \multicolumn{6}{|l|}{ Construction } \\
\hline Malpasset & -2 & 0 & -2 & -1 & -1 \\
\hline
\end{tabular}

The overall statistical analysis indicates no differences in groups' final rank results, and great differences comparing the expert reference value and groups' results. It also indicates that events' risk score moved towards overestimation or underestimation (shifted positively or negatively) according to its hazards categories (Aragonés, Moyano, \& Talayero, 2008; Sjöberg, Peterson, Fromm, Boholm, \& Hanson, 2005).

Nevertheless, it must be kept in mind that analyzing the reasons that led the groups to the reported results is not within the scope of this paper. Such behavior was expected and already stressed in literature (Schmidt, 2004; Sjoberg, 2011; Sjöberg, 2000a, 2000b; Slovic \& Västfjäll, 2010; Slovic, 1987). Instead, it focuses on showing to the participants that they adopted the same criteria to judge the risk and to score the events, inviting them to reflect upon it. Thenceforth, discuss their ideas and argumentations, organizing them, and introducing the concepts of risk, risk perception and risk assessment (as one of the course's aims). These are the findings approached in the following section. 


\section{In-class discussions}

The results presented in Tables 2 and 4 were discussed within respective groups. In such occasion, participants were encouraged to describe what they adopted as criteria for ranking the risk events and the reasons why those criteria were adopted by them. The groups' responses also converged and are described below.

It can be seen in Table 4, that the risk score of the events categorized as 'Chemicals' was overestimated (3-6 positions). All respondents described such events as an involuntarily imposed situation, where the real risk was unknown to those exposed, as well as to local authorities and emergency health services. Factors, such as high number of deaths, permanent impairment, long-term and delayed effects, omission from people in charge, environmental pollution and media coverage, were weighed and contributed to the overall analysis (Grasa, Navarro, Rubio, Pena, \& Santamaria, 2002).

Risk score of the events categorized as 'Environmental' (in this case environmental pollution due to oil tankers accidents) was slightly overestimated (2 points). Despite the fact that the rank values for these events are not statistically the same, as demonstrated by $p$-value in Table 2, the five groups overestimated the risk associated with these events, to a greater or lesser extent (Table 4). In such case, neglecting of duty and environmental pollution of large areas were predominantly reported by the groups as ranking criteria.

The risk score of events set up as 'Medical' hazards were, in general, underestimated. Taking L-tryptophane as a vitamin supplement was strongly underestimated (5 points), clearly because all respondents considered it as a voluntary risk. Thalidomide was slightly underestimated (2 points) because respondents also considered, in some way, taking medicines as a voluntary risk, once it was prescribed for pregnancy sickness symptom relief. Moreover, participants argued that side effects were unknown, and, as soon as the problem was detected, the drug was taken off the market and the prescription for pregnant women suspended. In this case, information reliability was also cited. Risks from silicone implants were underestimated (1 to 3 points). Participants considered it an aesthetic surgery procedure and not to a health problem, as a cardiac surgery, for instance. According to their comments, the casualties were spread throughout the years, not concentrated on a specific geographic area or on a specific population. Besides voluntariness, participants also considered it as a non-catastrophic and easily controllable situation.

Events categorized as 'Nuclear' hazards are ranked as the first 4 events according to the expert estimates. The degree of interdependence among systems components (i.e. people, equipment and procedures) of the nuclear technology is very high. Usually, accidents are fatal and control 
measures are very complex (Venables, Pidgeon, Simmons, Henwood, \& Parkhill, 2009). As presented in Table 4, with the exception of Chernobyl, which was slightly overestimated, the 3 other events were underestimated by the five groups. Chelyabinsk remained among the first four events in the rank, as well as Chernobyl. Its risk score was not at the top of the list, as were experts' estimates, but is ranked amongst the first three positions. Three Mile Island risk score, on the other hand, was strongly underestimated (6 positions). According to participants' opinion, the accident was controlled in time. The population was evacuated and no deaths were registered. Tokaimura accident was slightly underestimated (3 points). Participants argued that in spite of being a nuclear accident, there was no explosion or massive release of radioactive material. Despite the small amount of radioactive material released, local population was evacuated, and in participants' point of view, protected by authorities (those in charge of taking decisions). Furthermore, few deaths were registered and delayed effects were not reported. Participants considered that, in some way, the situation was under control.

At last, Malpasset Dam accident, a 'Construction' hazard, was slightly underestimated. When asked, respondents considered such accident as having a relatively minor impact compared with the others.

Gathering all the described characteristics together, some observations could be made within each group. Firstly, the events were interpreted and judged according to common criteria within each group (intra-groups and also inter-groups). Secondly, risk acceptability was framed according to hazards categories (Aragonés et al., 2008). Thirdly, there was a remarkable difference between expert analysis and groups' analysis (Sjöberg, 1999).

At this point, some questions were directed at the students, taking into account the above observations. They were asked about what drove the ranking process and why there were so many differences between expert estimates and groups' analysis, as well as the reliability and suitability of the adopted criteria. Participants were encouraged to observe their own evaluation regarding the risk of the activities, substances and technologies under discussion and compare their analysis with expert estimates.

After comparing the results, participants could realize that their adopted criteria for risk analysis, and thus to risk acceptability, were not technical and scientific ones. Judgment values and criteria used to rank the events according to its risk were based on qualitative characteristics. Among them: voluntariness, misinformation, media coverage, omission, control or lack of control over the activity, permanent impairment, long-term and delayed effects, nature of the hazard, and promptness response (Renn, 2004; Stewart, Luria, Reid, Lyons, \& Jarvis, 2010). For instance, not only the 
number of deaths, but also the cause and manner of death, which evoke feelings of dread to different extents, clearly influenced the risk acceptability. Deaths from risks imposed involuntarily, from risks considered out of one's control, or from particularly dread activity were given greater weight in groups' risk acceptability. In their opinion, deaths arising from a chemical plant accident were considered 'much worse' than deaths or impairment caused by taking medicines or as a consequence of floods. Malpasset dam collapse exemplifies this statement. Despite the high number of casualties, such accident was clearly associated to natural hazards (Terpstra, 2011). Small cracks had already been discovered in the dam wall and grew rapidly, population was given no warnings; and even so, participants attributed the accident to the abnormal rain that caused the dam rupture. These observations corroborate to the fact that large constructions are perceived as a benefit by general public, thus enhancing risk acceptability (Renn, 2004). Regarding the nature of the hazard, it was also clear that some hazard categories were more feared than others. Accidents categorized as chemical and environmental hazards were shifted positively (less acceptable), while those categorized as construction, medical and nuclear were shifted negatively (more acceptable). This is known as 'framing before hazard', another subjective perception characteristic of real risks (Lima, 2004).

During the ensuing discussion, participants were introduced to the expression 'risk perception', aiming to provide a scientific meaning to the estimate based on emotions and subjective values carried out by them, e.g. fear, feelings of dread, and threat among second and third party people (Renn, 2004; Slovic, 1987). They could notice that risk, in the proposed activity, was evaluated according to their subjective perceptions, an experiential mode of thinking in which facts and information are filtered through social and cultural perceptual lenses and, usually, also related to the extent to which the situation can be recalled or imagined (Dietz, Scott Frey, \& Rosa, 1996; Slovic, Finucane, Peters, \& MacGregor, 2004). Judgments were based not on what they critically knew about the event, substance or technology relying on scientific data, but rather handled by feelings regarding it. Values, emotions and beliefs came prior to risk analysis and directed the process. In such cases, the severity of outcomes of a hazard, rather than risk itself, overrules the overall analysis. And, as a consequence, the risk analysis tends to differ from expert estimates (Sjörberg, 1999; 2000).

Next, participants were asked to define the word risk. Multiple conceptions of risk, found in literature, were shown to them: risk as hazard; risk as probability; risk as consequence; and risk as potential adversity or threat (Renn, 2004; Slovic \& Weber, 2002). Finally, as relevant outcomes 
from this activity, some considerations were made and are outlined in the following paragraphs.

In a broad sense, "risk refers to the possibility that human actions or events lead to consequences (outcomes) that affect aspects of what humans value” (Renn, 1998b, p. 51). Nevertheless, risk means different things to different people and many factors underlie those meanings. In other words, something's risk strongly depends on the semantic context in which the word risk is used, leading participants to realize that context matters in any risk assessment process (Renn, 1998a; ISO, 2009a, 2009b, 2009c).

In technical risk assessment, defining context implies specifying what is at stake before calculating probabilities of unwanted consequences (Sjöberg, 2000a). Likelihood of negative outcomes, to be properly assessed within a well-defined context, requires hazard to be recognized according to a given value system, whatever it is. Otherwise, no confident results will be obtained (Renn, 1998a).

Value systems are fundamental in selecting and framing risks, and are closely related to social context. They comprise clear rules, statements or endpoints, without which technical risk assessment, known as a rule/reason based process tends to be replaced by an affect-driven process: the subjective perception and analysis of risk (Henwood, Pidgeon, Sarre, Simmons, \& Smith, 2008). In such cases, risk itself arises from an intuitive and instinctive mode of thinking that transforms uncertainty and threatening aspects of the environment into affective responses to danger, such as fear, dread and anxiety (Slovic \& Peters, 2006). A rule/reason based process, on the other hand, brings logic, reason and scientific deliberation to the risk assessment process and should reflect technical expertise and scientific knowledge as much as possible, since 'real' victims are at stake (Slovic et al., 2004).

Risk perception, according to Pidgeon et al, can be defined as "people's beliefs, attitudes, judgments and feelings, as well as social or cultural values and dispositions that people adopt towards hazards” (Pidgeon, Hood, Jones, Turner, \& Gibson, 1992, p. 89), or any issue of concern, and how they model the outcomes' likelihood, costs and benefits (Sjöberg, 2000a).Consequently, risk perception may not, and usually does not, agree with technical-scientific definition of risk and its assessment (Sjöberg, 1999). Perceived risk is a challenging aspect to cope with, since it pervades risk assessment process at every stage, from drawing context and hazard identification, to deciding endpoints and consequences to be considered into the analysis. Therefore, a careful identification and selection of concerns and of evaluative criteria are strongly necessary to eliminate subjectivity from the technical risk assessment process, whenever and wherever possible (Renn, 1998a; Bostrom, 1997). 


\section{Conclusion}

The activity allowed the word 'risk' to be explored by participants, simply by analyzing events, technologies and substances previously known, as well as comparing their analysis with expert analysis.

Participants' opinions and statements regarding meanings of risk, risk perception and risk assessment were collected and compiled. The ensuing discussion involved the resignification of the ideas raised by the groups, giving them a scientific meaning inserted into a technical context.

More than deepening in one or another concept of risk, such activity gave the participants clues of what could be approached in more detail regarding risk universe, showing them the many dimensions that are inherent to risk analysis (e.g. social, cultural and scientific ones). It is an activity in which participants shared opinions based on their previous knowledge and began to deal with the idea of evaluating risk in a scientifically reasoned basis.

The proposed practice, developed as an attempt to overcome the lack of instructional resources to teach risk in an interactive way, presented consistent results for the five groups, and thus becoming an alternative resource to be used as an introductory practice in short duration courses.

\section{References:}

Alli, B. O. (2008). Fundamental Principles of Occupational Health and Safety (p. 199). Geneva: International Labour Office.

Althaus, C. E. (2005). A disciplinary perspective on the epistemological status of risk. Risk Analysis: An Official Publication of the Society for Risk Analysis, 25(3), 567-88. doi:10.1111/j.1539-6924.2005.00625.X

Aragonés, J. I., Moyano, E., \& Talayero, F. (2008). Categorizing sources of risk and the estimated magnitude of risk. The Spanish Journal of Psychology, 11(1), 85-93. doi:10.1017/S1138741600004145

Aven, T. (2010). Misconceptions of Risk (First., p. 240). Chichester, UK: John Wiley \& Sons, Ltd. doi:10.1002/9780470686539

Aven, T. (2011). A risk concept applicable for both probabilistic and nonprobabilistic perspectives. Safety Science, 49(8-9), 1080-1086. doi:10.1016/j.ssci.2011.04.017

Aven, T. (2012a). Foundational issues in risk assessment and risk management. Risk Analysis : An Official Publication of the Society for Risk Analysis, 32(10), 1647-56. doi:10.1111/j.1539-6924.2012.01798.x

Aven, T. (2012b). The risk concept-historical and recent development trends. Reliability Engineering \& System Safety, 99(0951), 33-44. doi:10.1016/j.ress.2011.11.006

Aven, T., \& Kristensen, V. (2005). Perspectives on risk: review and discussion of the basis for establishing a unified and holistic approach. 
Reliability Engineering \& System Safety, 90(1), 1-14. doi:10.1016/j.ress.2004.10.008 Aven, T., Renn, O., \& Rosa, E. A. (2011). On the ontological status of the concept of risk. Safety Science, 49(8-9), 1074-1079. doi:10.1016/j.ssci.2011.04.015

Badri, A., Gbodossou, A., \& Nadeau, S. (2012). Occupational health and safety risks: Towards the integration into project management. Safety Science, 50(2), 190-198. doi:10.1016/j.ssci.2011.08.008

Boholm, M. (2012). The semantic distinction between "risk" and "danger": a linguistic analysis. Risk Analysis: An Official Publication of the Society for Risk Analysis, 32(2), 281-93. doi:10.1111/j.1539-6924.2011.01668.x

Borys, D. (n.d.). The Future of Health \& Safety Education. Retrieved from http://www.ohseducationaccreditation.org.au/wp-

content/uploads/2013/06/2000_The_Future_of_OHS_Education_Borys_SIA. pdf

Bostrom, A. (1997). Risk Perceptions: "Experts” vs. "Lay People.” Duke Environmental Law \& Policy Forum, 8(1), 101-113. Retrieved from http://scholarship.law.duke.edu/delpf/vol8/iss1/8

Brosseau, L., \& Fredrickson, A. (2009). Assessing outcomes of industrial hygiene graduate education. Journal of Occupational and Environmental Hygiene, 6(5), 257-66. doi:10.1080/15459620902754372

Canadian Centre for Occupational Health and Safety. (2006). Canadian Centre for Occupational Health and Safety. Risk Assessment. Retrieved from http://www.ccohs.ca/oshanswers/hsprograms/risk_assessment.html

Canadian Centre for Occupational Health and Safety. (2009). Canadian Centre for Occupational Health and Safety. Hazard an Risk. Retrieved from http://www.ccohs.ca/oshanswers/hsprograms/hazard_risk.html

Caponecchia, C. (2010). It Won't Happen to Me: An Investigation of Optimism Bias in Occupational Health and Safety. Journal of Applied Social Psychologyial Psychology, 40(3), 601-617. doi:10.1111/j.15591816.2010.00589.x

Cleeland, B. (2011). Contributing Factors to the Emergence of Systemic Risks. Technology Assessment - Theory and Practice, 3(20), 13-21. doi:not found

Cohen, J. (1988). Statistical power analysis for the behavioral sciences (p. 474). Hillsdale, NJ, England: Lawrence Erlbaum Associates.

Covitt, B. A., Gomez-Schmidt, C., \& Zint, M. T. (2005). An Evaluation of the Risk Education Exploring Environmental Issues: Focus on Risk. The Journal of Environmental Education, 36(2), 3-14. doi:10.3200/JOEE.36.2.313

Covvit, B. A., Harris, C. B., \& Anderson, C. W. (2013). Evaluating Scientific Arguments with Slow Thinking. Science Scope, 37(3), 44-47. 
Dietz, T., Scott Frey, R., \& Rosa, E. (1996). Risk, Technology, and Society. In R. E. Dunlap \& W. Michelson (Eds.), Handbook of Environmental Sociology. Westport: Greenwood Press.

Environmental Protection Agency. (2012). EPA Risk Assessment. Risk Assessment. Retrieved from http://epa.gov/riskassessment/basicinformation.htm\#arisk

European Agency for Safety and Health at Work. (2010). Mainstreaming occupational safety and health into university education (p. 176). Luxembourg. doi:10.2802/12315

European Agency for Safety and Health at Work. (2013). Green jobs and occupational safety and health: Foresight on new and emerging risks associated with new technologies by 2020 (p. 216). Luxembourg. doi:10.2802/39554

Gardner, G., Jones, G., Taylor, A., Forrester, J., \& Robertson, L. (2010). Students' Risk Perceptions of Nanotechnology Applications: Implications for science education. International Journal of Science Education, 32(14), 1951-1969. doi:10.1080/09500690903331035

Grasa, G., Navarro, V., Rubio, O., Pena, J. A., \& Santamaria, J. (2002). A comparative study of risk perception in small and large communities where chemical industries are present. Journal of Loss Prevention in the Process Industries, 15(6), 525-530. doi:10.1016/S0950-4230(02)00033-5

Henwood, K., Pidgeon, N., Sarre, S., Simmons, P., \& Smith, N. (2008). Risk, framing and everyday life: Epistemological and methodological reflections from three socio-cultural projects. Health, Risk \& Society, 10(5), 421-438. doi:10.1080/13698570802381451

Hovden, J., Albrechtsen, E., \& Herrera, I. A. (2010). Is there a need for new theories, models and approaches to occupational accident prevention? Safety Science, 48(8), 950-956. doi:10.1016/j.ssci.2009.06.002

International Risk Governance Council. (2005). Risk governance - towards an integrative approach (p. 157). Geneve. doi:10.1515/9783110285161.219 International Risk Governance Council. (2010). The Emergence of Risks: Contributing Factors (p. 60). Geneva: International Risk Governance Council.

ISO. (2009a). IEC 31010:2009. Risk management - Risk assessment techniques. ISO. Retrieved from http://www.iso.org

ISO. (2009b). ISO 31000:2009. Risk management - Principles and guidelines. iso. Retrieved from http://www.iso.org

ISO. (2009c). ISO Guide 73:2009. Risk management -Vocabulary. ISO. Retrieved from www.iso.org

Jackson, J., Allum, N., \& Gaskell, G. (2006). Bridging Levels of Analysis in Risk Perception Research: The Case of the Fear of Crime [84 paragraphs]. 
Forum Qualitative Sozialforschung / Forum: Qualitative Social Research, 7(1), Art.20. doi:not found

Jonckheer, P., \& De Brouwer, C. (2009). Education in environmental health of health care professionals: what needs to be done? Environment International, 35(4), 694-9. doi:10.1016/j.envint.2009.01.004

Koukoulaki, T. (2010). New trends in work environment - New effects on safety. Safety Science, 48(8), 936-942. doi:10.1016/j.ssci.2009.04.003

Learning Lab. (2005a). HAZARDCARDS. Cards. Retrieved from http://www.hazardcards.com/cards.php

Learning Lab. (2005b). HAZARDCARDS. About. Retrieved from http://www.hazardcards.com/about.php

Learning Lab. (2005c). HAZARDCARDS. Hazard Values. Retrieved from http://www.hazardcards.com/research.php?aid=31

Lima, M. L. (2004). On the influence of risk perception on mental health: living near an incinerator. Journal of Environmental Psychology, 24(1), 7184. doi:10.1016/S0272-4944(03)00026-4

National Research Council. (2000). Safe Work in the 21st Century: Education and Training Needs for the Next Decade's Occupational Safety and Health Personnel (p. 264). Washington, DC: National Academic Press.

Nielsen, K. H. (2005). Between understanding and appreciation. Current science communication in Denmark. Journal of Science Communication, 4(4), 1-9. doi:not found

Pickering, A., \& Cowley, S. (2010). Risk Matrices: implied accuracy and false assumptions. Journal of Health \& Safety Research and Practice, 2(1), 9-16. doi:not found

Pidgeon, N. F., Hood, C., Jones, D., Turner, B., \& Gibson, R. (1992). Risk Perception. In Study Group on Risk (Ed.), Risk: analysis, perception and management (pp. 89-134). London: The Royal Society.

Pisaniello, D. L., Stewart, S. K., Jahan, N., Pisaniello, S. L., Winefield, H., \& Braunack-Mayer, A. (2013). The role of high schools in introductory occupational safety education - Teacher perspectives on effectiveness. Safety Science, 55, 53-61. doi:10.1016/j.ssci.2012.12.011

Renn, O. (1998a). The role of risk perception for risk management. Reliability Engineering \& System Safety, 59(1), 49-62. doi:10.1016/S09518320(97)00119-1

Renn, O. (1998b). Three decades of risk research: accomplishments and new challenges. Journal of Risk Research, 1(1), 49-71. doi:10.1080/136698798377321

Renn, O. (2004). Perception of risks. Toxicology Letters, 149(1-3), 405-13. doi:10.1016/j.toxlet.2003.12.051

Rosen, M. A., Caravanos, J., Milek, D., \& Udasin, I. (2011). An Innovative Approach to Interdisciplinary Occupational Safety and Health Education. 
American Journal of Industrial Medicine, 54(7), 515-520. doi:10.1002/ajim.20964

Schmidt, B. M. (2004). Investigating risk perception : a short introduction, (October), 1-16.

Singley, J. A. (2004). Hazard versus risk. Chemical Health and Safety, 11(1), 14-16. doi:10.1016/j.chs.2003.09.016

Sjoberg, L. (2011). Dynamics of risk perception.

Sjöberg, L. (1999). Risk Perception by the Public and by Experts: A Dilemma in Risk Management. Research in Human Ecology, 6(2), 1-9.

Sjöberg, L. (2000a). Factors in Risk Perception. Risk Analysis, 20(1), 1-11. doi:10.1111/0272-4332.00001

Sjöberg, L. (2000b). The Methodology of Risk Perception Research, 407418.

Sjöberg, L., Peterson, M., Fromm, J., Boholm, Å., \& Hanson, S. (2005). Neglected and overemphasized risks: the opinions of risk professionals. Journal of Risk Research, 8(7-8), 599-616. doi:10.1080/13669870500062576

Slovic, P. (1987). Perception of Risk. Science, 236(4799), 280-285. doi:10.1126/science.3563507

Slovic, P., Finucane, M. L., Peters, E., \& MacGregor, D. G. (2004). Risk as analysis and risk as feelings: some thoughts about affect, reason, risk, and rationality. Risk Analysis: An Official Publication of the Society for Risk Analysis, 24(2), 311-22. doi:10.1111/j.0272-4332.2004.00433.x

Slovic, P., \& Peters, E. (2006). Risk Perception and Affect. Current Directions in Psychological Science, 15(6), 322-325. doi:10.1111/j.14678721.2006.00461.x

Slovic, P., \& Västfjäll, D. (2010). Affect, Moral Intuition, and Risk. Psychological Inquiry, 21(4), 387-398. doi:10.1080/1047840X.2010.521119 Slovic, P., \& Weber, E. U. (2002). Perception of Risk Posed by extreme Events. In Risk management strategies in an Uncertain World (pp. 1-21). Palisades. Retrieved

from https://www0.gsb.columbia.edu/mygsb/faculty/research/pubfiles/5461/perce ption of risk.pdf

Stewart, A. G., Luria, P., Reid, J., Lyons, M., \& Jarvis, R. (2010). Real or illusory? Case studies on the public perception of environmental health risks in the north west of England. International Journal of Environmental Research and Public Health, 7(3), 1153-73. doi:10.3390/ijerph7031153

Takala, J., \& Hamalainen, P. (2009). Globalization of risks. African Newsletter on Occupational Health and Safety, 19(3), 70-73.

Terpstra, T. (2011). Emotions, Trust, and Perceived Risk: Affective and Cognitive Routes to Flood Preparedness Behavior. Risk Analysis, 31(10), 1658-1675. doi:10.1111/j.1539-6924.2011.01616.x 
Venables, D., Pidgeon, N., Simmons, P., Henwood, K., \& Parkhill, K. (2009). Living with nuclear power: A Q-method study of local community perceptions. Risk Analysis: An Official Publication of the Society for Risk Analysis, 29(8), 1089-104. doi:10.1111/j.1539-6924.2009.01259.x

Zalk, D. M., \& Nelson, D. I. (2008). History and evolution of control banding: a review. Journal of Occupational and Environmental Hygiene, 5(5), 330-46. doi:10.1080/15459620801997916

Zinn, J. O. (2008). Heading into the unknown: Everyday strategies for managing risk and uncertainty. Health, Risk \& Society, 10(5), 439-450. doi:10.1080/13698570802380891

Zint, M. T. (2001). Advancing environmental risk education. Risk Analysis: An Official Publication of the Society for Risk Analysis, 21(3), 417-26. doi:10.1111/0272-4332.213122 